\title{
From Music to Language and Back ${ }^{1}$
}

I grew up in a musical home [...] I learnt to think in music, and I still do to this day.

Barenboim (L3)

Music can [...] become something that is used not to escape from the world, but rather to understand it.

Barenboim (L1)

\section{Introduction}

This article presents a case study of an intermodal translation which goes from music tolanguage and then back to music. The data come from five radio lectures titled "In the Beginning Was Sound" which were delivered at week intervals in 2006 by conductor and pianist Daniel Barenboim as part of the series of annual $B B C$ Reith Lectures, and from discussions which followed each lecture. ${ }^{2}$ In line with the tradition of the series, the lectures

1 This article is a revised and expanded version of the plenary talk titled "From Music to Language and Back" that I gave at the Intersemiotic Translation Conference, 25-27 September 2013, Łódź, Poland. It appeared in 2018 under the same title in LaMiCuS [Language Mind Culture and Society] 2: 82-100; https://doi.org/10.32058/LAMICUS-2018-003, and it is reprinted here with kind permission from the Journal's Publishers - the Polish Cognitive Linguistics Association. The article also draws upon my earlier paper titled "LIFE IS MUSIC: A Case Study of a Novel Metaphor and Its Use in Discourse", which appeared in: Barbara Dancygier, José Sanders and Lieven Vandelanotte (eds.) (2012). Textual Choices and Discourse. A View from Cognitive Linguistics. (137-155). Amsterdam: Benjamins. https://doi.org/10.1075/bct.40.08gor. The relevant parts are reprinted here with the Publisher's kind permission granted for this edited volume.

2 The series has been broadcast for over 60 years; for the Reith Lectures archives (which contain both the audio and transcript versions of the lectures), see URL: http:// 
had a truly international audience as they were delivered in five different countries, each related to Barenboim's musical career at some point in his life. ${ }^{3}$ From the information provided during the discussions, we know also that the audience comprised people of different walks of life, including professional musicians, composers, music therapists, psychologists, architects, filmmakers, writers, philosophers, journalists, and students.

My discussion will begin with Barenboim's ideas about the place of music in society and then it will move on to his own insights on various aspects of individual, social and political life that he, as a practising musician, has gained from music (section 2). In the main part of the article, I will focus on selected aspects of his music-derived knowledge about life that Barenboim first described using the verbal mode and then translated his linguistic descriptions back onto music (section 3). My analysis will be framed in terms of the dynamic approach to metaphor developed by Müller (2008), Müller \& Tag (2010) and Kolter et al. (2012) (see also Górska 2014a; 2014b; Hampe 2017) and the blending theory (Fauconnier 1997; Fauconnier \& Turner 1998; 2002). It will be argued that through multimodal construction metaphors created by Barenboim have a high degree of contextual activation and, more importantly, his rhetoric achieves its persuasive objectives in a highly original and easy to comprehend manner. On the other hand, shifting of his viewpoint from that of someone who has been learning about life from music to that of the BBC lecturer will be regarded as Barenboim's rhetorical technique of establishing common ground with the audience. ${ }^{4}$

\section{Learning from Music}

Having been brought up in a musical home where both of his parents taught piano, Barenboim, as he himself admits, learned to think in music and [he] still [does] to this day" (L3). For him, music has always been a teacher from whom he learnt a lot about human condition and various aspects of life. From the perspective of cognitive theories of metaphor, we can thus say that Barenboim's personal life has been guided by two metaphors:

(1) MUSIC IS A TEACHER and LIFE IS MUSIC.

www.bbc.co.uk/radio4/features/the-reith-lectures/archive/. The total time of Barenboim's lectures was 1h. $59 \mathrm{~min}$. and that of discussions $-1 \mathrm{~h} .55 \mathrm{~min}$.

${ }^{3}$ See data sources below.

${ }^{4}$ For intersubjective and multimodal construal of viewpoint see Vandelanotte (2017) and the literature cited therein. 
At the same time, over the years Barenboim has become very "unhappy [...] about the place of music in a society" (L1) which is much more concerned with the visual and which, through constant attacking of the ear with "muzak" has, as he puts it, "anaesthetized" (L2) this exceptionally intelligent organ of perception. Therefore, the urgent need to change our attitude to music is one of the main concerns of the whole lecture series. The excerpt in (2) illustrates this point:

(2) [C]lassical music as we know it [...] will not survive unless we make a radical effort to change our attitude to it and unless we take it away from a specialised niche that it has become, unrelated to the rest of the world, and make it something that is essential to our lives. Not something ornamental, not only something enjoyable, not only something exciting, but something essential [...]. I think we should all have the possibility to learn not only it but to learn from it [...] there's so many things that you can learn from the music towards understanding the world, if you think of music as something essential. (L3)

So what insights "towards understanding the world" has Barenboim himself gained from music? At this stage, I will briefly summarize the various kinds of music-derived knowledge that he described only verbally. One kind of Barenboim's music-derived insights is about the very nature of life, and what he describes as the "fluidity of life" is for him "best expressed in music" (L3). Music, as he puts it, comes out of nothing, and "the present of the first note [...] is nothing but a transition" (L3). This leads him to say that "the most clearly definable [...] fact that music teaches us as human beings [is] that everything, without an exception, has a past, a present, and a future". It is therefore from music that he has learnt to accept both "the fluidity of life" and also "the fact that nothing, absolutely nothing, is completely independent and solid, but everything that [he] think[s] and feel[s] is dependent on this fluidity of life" (L3).

Another important lesson that he has "learned from music for life" is about experiencing the unity of things. On the one hand, as he argues, "conflict, difference of opinion, is the very essence of music [...]. You see that in a Bach fugue, you see that in Mozart concertos and operas" (L2). And yet, as he explains, we have the "capacity to bring all the different elements together in a sense of proportion so that they lead to a sense of a whole" (L2).

For Barenboim, music has also revealed a lot about the relation between an individual and a group. This topic recurs on several occasions in his lectures. By way of illustration, let me refer here to an excerpt given in (3) which comes from the discussion after the first lecture. When criticizing the idea that classical music is elitist, Barenboim vigorously argued for the opposite view claiming that: 
(3) [M] aking music and playing it in an orchestra [are] the best way to understand democracy [...]. The oboe plays the most wonderful tune in a slow movement of a Brahms symphony, and the whole orchestra, all ninety or ninety-five of them, and the conductor with the big ego, is following him [...]. He's the king of the world - and that lasts for eight bars! [...] And then, on the ninth bar, he [...] goes back in the society, in the collective, and he has to do what ninety-five people have been doing for him [...]. (LD1)

Not surprisingly, therefore, for Barenboim the language of music is "the language of the continuous dialogue" and, moreover, "the art of playing music is the art of simultaneous playing and listening" (L4). As he explains it, when you play music "You have to be able to express yourself, otherwise you are not contributing to the musical experience, but at the same time it is imperative that you listen to the other. You have to understand what the other is doing" (L4). These were some of the insights that led Barenboim and Edward Said, a Palestinian intellectual, to establish in the late 1990s what is now known as the West Eastern Divan orchestra in which equal number of Arab and Israeli musicians play together. For them, as Barenboim, observes:

(4) Music is the common framework, their abstract language of harmony [...] when emotion and intellect are in tune, it is easier also for human beings and for nations to look outward as well as inward. And therefore through music we can see an alternative social model, a kind of practical Utopia, from which we might learn about expressing ourselves freely and hearing one another. (L4)

To recapitulate, Barenboim makes it clear that he has gained an understanding of diverse aspects life from music. Therefore, in his personal experience, the life is music metaphor is intimately linked with the personification of music which, as he maintains, has always been his TEACHER.

\section{Intermodal Translation in the Lectures' Rhetoric}

Relying on the guidance of music in his personal life, in his BBC lectures Barenboim uses the LIFE IS MUSIC metaphor (cf. (1)) as a recurring leitmotif and his main rhetorical device for persuading the audience that we can understand diverse aspects of individual, social, and political life through music. In terms of the blending theory, this metaphor can be described as a complex integration network in which LIFE and MUSIC function as the most salient inputs. On the level of language use, particular linguistic expressions via which Barenboim 
explicitly characterizes LIFE in-terms-of MUSIC will be viewed as metaphorical expressions (or, in Müller's (2008) terms, verbal metaphors) which trigger the on-line construction of the dynamically evolving integration network.

Deliberately referring to LIFE AS MUSIC on several occasions, ${ }^{5}$ Barenboim also uses a number of less schematic metaphors to shed light on a particular kind of relationship between the two domains. Of these, the metaphor having the highest degree of activation in his lectures is based on Barenboim's experientially derived novel metaphor which was phrased in (1) as MUSIC IS A TEACHER. ${ }^{6}$ In terms of discourse organization, the frequent use of this metaphor serves to unite the overall lecture series at a more specific level. Arguably, this metaphor also fulfils another important discourse function. Namely, by using it, Barenboim constantly shifts his viewpoint from that of the lecturer-

${ }^{5}$ Also Sue Lawley, the BBC Chair, frequently makes explicit reference to this metaphor when introducing individual lectures and/or closing them up, when mediating between Barenboim and the members of the audience during the discussions, and also to characterize the main objective of the lecture series as a whole.

${ }^{6}$ According to Müller's (2008) dynamic theory, metaphoricity, i.e. the process of "seeing" one thing in terms of another, is a matter of activation which can be empirically observable: it can be correlated with the amount of activation indicators such as repetition, elaboration, specification or multimodal construction (2008: 198-200). With reference to degrees of activation, the dynamic category of metaphors is characterized in terms of sleeping and waking metaphors that form two end points of the metaphoricity scale. "[A] sleeping metaphor is a metaphor whose metaphoricity is potentially available to an average speaker/listener, writer/reader [...], but there are no empirical indications of activated metaphoricity" (2008: 198). A waking metaphor, by contrast, is "surrounded by metaphoricity indicators" and "the more metaphoricity indicators surround such a metaphor, the more it is waking" (2008: 198). Both conventional and novel metaphors may exhibit different degrees of metaphoricity depending on the context of use (see Müller 2008: 198). Referring to the idea of iconic motivation and to the context of interaction, Müller argues that the more cues direct the attention of the interlocutors to the metaphoric quality of an expression, the higher the degree of cognitive activation of metaphoricity in the producer and also potentially in the addressee. As Cienki and Müller put it, "clusters of attention-getting cues produce interactive foregrounding of metaphoricity and since what is interactively foregrounded is also interpersonally foregrounded, metaphoricity should in these cases be highly activated interpersonally" (2008: 495). Note further that, in the revised model of the dynamic category of metaphors (see Tab. 1 in Kolter et al. 2012: 203), multimodal metaphors always qualify as waking, and whenever their meaning is rendered explicit by a metacommentary they reach the highest level of metaphoricity. Accordingly, since their meaning was made explicit on several occasions in the lecture series, the metaphoricity of both life is music as well as music is a teacher is highly activated. For more on activation of metaphoricity through multimodal construction see, e.g., Müller and Tag 2010; Forceville 2013; Górska 2014a; 2014b; 2017; Müller 2017; Szawerna 2017; Feyaerts, Brône and Oben 2017. 
teacher to that of someone who has learnt about LIFE from MUSIC and for whom, as he would argue again and again, the latter domain is far more immediate and easier to comprehend in and of itself than that of the former. In effect, his objective is merely to show the many things he himself has learned about "real life" from MUSIC (LD1). Naturally, by putting himself on equal footing with his audience Barenboim establishes common ground with it.

Of the diverse things that we can, as Barenboim himself did, learn from music, I will now consider in a much greater detail some of Barenboim's musical insights that he presented to the BBC audience in a multimodal manner, giving first a verbal description and then translating it back onto music.

In his first lecture Barenboim's main aim was to draw some "connection between the inexpressible content of music and in many ways the inexpressible content of life" (L1). The excerpts in (5) and (6) illustrate his main argument:

(5) The first thing we notice about sound [...] is that it doesn't live in this world. Whatever concert took place in this hall [...], the sounds have evaporated, and they are ephemeral. So although sound is a very physical phenomenon, it has some inexplicable metaphysical hidden power. The physical aspect that we notice first is that sound does not exist by itself, but has a permanent constant and unavoidable relation with silence. (L1)

(6) [S] ound reacts to silence much like the law of gravity tells us, that if you lift an object from the ground you have to use a certain amount of energy to keep it at the height to which you have brought it up to. You have to provide additional energy, otherwise the object will fall back to the law of gravitation on the ground. But this is exactly what sound does with silence. I play again the same note, I play it, I give a certain amount of energy, and if I do nothing more to it, it will die. [plays one note plus brief silence] This is the length of the duration of the life of this $C$ sharp produced by my finger on this piano [...]. What did I say just now? The note dies. And this is the beginning of the tragic element in music, for me. (L1)

In terms of the blending theory, we can say that Barenboim achieves his rhetorical objective of establishing a "connection between the inexpressible content of music and in many ways the inexpressible content of life" by constructing the Life of a Musical Sound blend (cf. Tab. 1). 
From Music to Language and Back

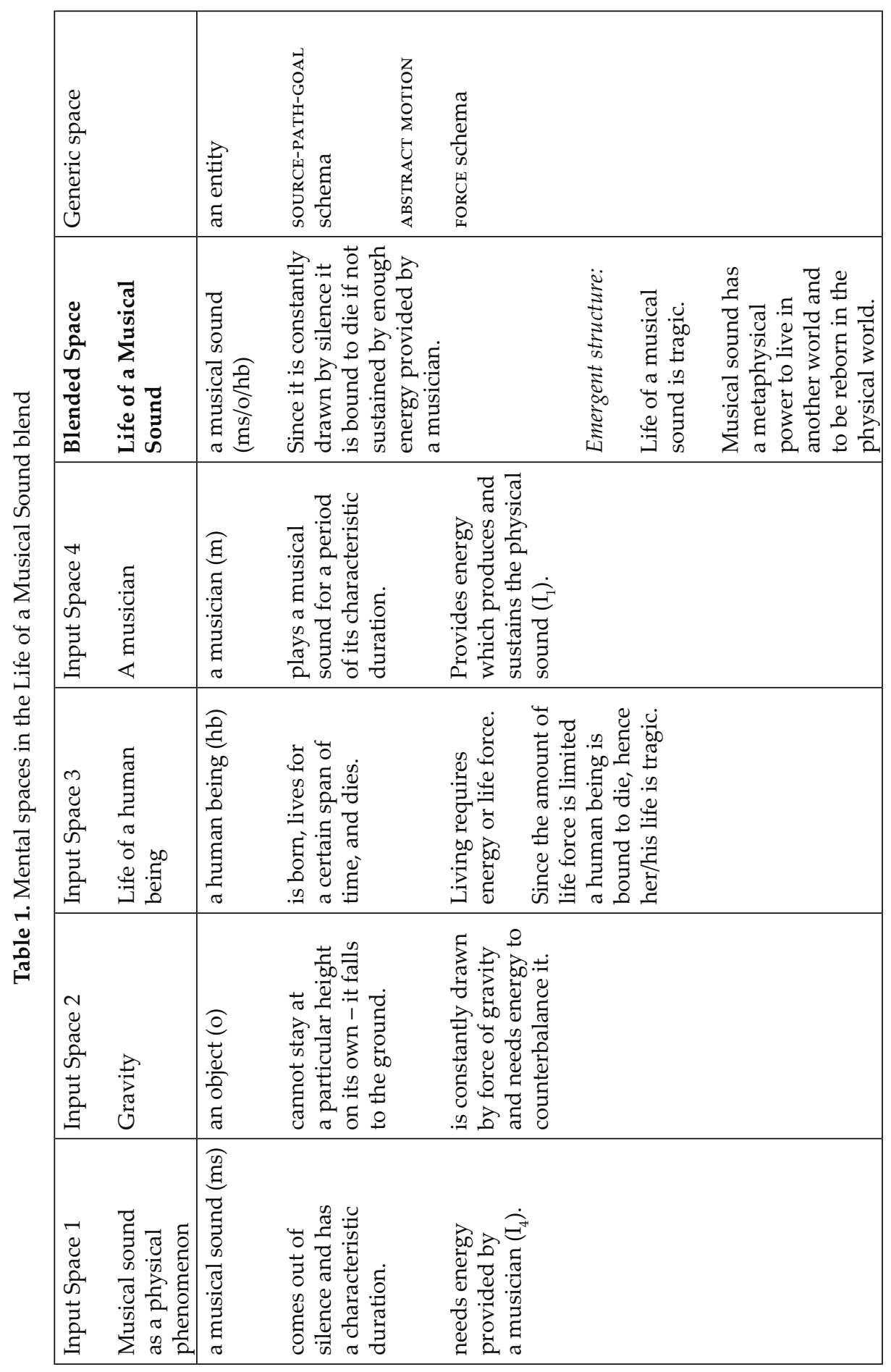


Specifically, the underlined expressions in (5) and (6) trigger the process of setting up an integration network and constructing a blended space as its crucial part. ${ }^{7}$ This blend involves partial structures from four input spaces: Musical Sound as a Physical Phenomenon $\left(\mathrm{I}_{1}\right)$, Gravity $\left(\mathrm{I}_{2}\right)$, Life of a Human Being $\left(\mathrm{I}_{3}\right)$, and the Musician space $\left(\mathrm{I}_{4}\right)$. In the context of the blend, the musical sound has some physical properties of sounds in $I_{1}$ - it has a particular duration, and some properties of objects in $I_{2}-$ it is drawn by force; it inherits a conception of life with three different stages, birth - life - span - death, from $\mathrm{I}_{3^{\prime}}$ and from $\mathrm{I}_{4}$ - the idea that a musician is capable of sustaining sound as a physical phenomenon. When the structures from the four inputs are integrated, the blended concept of the tragic life of a musical sound emerges: since the force of silence acts like gravity, the lifespan of a musical sound as a physical phenomenon depends on the counterforce which is provided by a musician (from $\mathrm{I}_{3}$ ); and thus being constantly drawn by the force of silence and totally dependent on the limited amount of energy provided by a musician, the musical sound is bound to die (cf. (6)), hence its life, like that of a human being, is tragic. This blend-specific scenario of the tragic life of a musical sound is further elaborated in the following way: since the musical sound (unlike a human being) has some metaphysical hidden power, it continues to live in another world (cf. (5)), and, moreover, it will be "reborn" in the physical world whenever a musician provides to it his or her energy which will counterbalance the force of silence. Note also that in the generic space, the relevant image schemas (Johnson 1987) and abstract motion (Langacker 1987) capture common structure and organization shared by the inputs and define the main cross-space correspondences between them.

Clearly, it is the blended conception of the musical sound that allows Barenboim to convey the idea of the "inexpressible content of music". In the context of the blend, it can be interpreted in terms of the emergent aspects of the scenario: even though the life of a musical sound is ephemeral and tragic, the sound itself has its own metaphysical hidden power of returning to reality, which is only induced by a performing musician.

As indicated in (6), the correspondence between the length of the musical sound's duration (in $\mathrm{I}_{1}$ ) and the life-span of a human being (in $\mathrm{I}_{3}$ ) was expressed by both the verbal and the musical mode. Drawing upon

${ }^{7}$ For overviews of Conceptual Blending, also known as Conceptual Integration Theory see, e.g. Fauconnier and Turner (2002: 44-50); Libura (2007: 11-66); Dancygier and Sweetser (2014: 73-99); Oakley and Pascual (2017). 
Forceville and Urios-Aparisi' characterization of multimodal metaphors (2009a: 4) as well as the dynamic approach to metaphor (Müller 2008: 95-111; Kolter et al. 2012), I will regard this correspondence as a verbomusical metaphor, which can be phrased as:

(7) THE LENGTH OF A MUSICAL SOUND'S DURATION IS THE LIFE-SPAN OF A HUMAN BEING.

This personification of sound qualifies as a verbo-musical metaphor on account of both the distribution of the metaphorical source and target across two modalities and the crucial role of the verbal context in interpreting the duration of the sound played by Barenboim in terms of the life-span of a human being (cf. in particular the phrase "the duration of the life of this C sharp" in (6)). The fact that two modalities are involved conjointly, increases the degree of contextual activation of this metaphor, ${ }^{8}$ and in effect renders the idea of the sound's life-span highly salient, making the blended conception of the tragic life of a musical sound more memorable. Undoubtedly, the use of the verbo-musical metaphor also contributes to the originality of Barenboim's rhetorical style.

As might be expected, this personification of sound is driven by one overarching goal of constructing blended concepts - that of "achieving human scale" (Fauconnier and Turner 2002: 322). Once the level of human scale is achieved, "it is natural for us to have the impression that we have direct, reliable, and comprehensive understanding"; and, as Fauconnier and Turner (2002: 323) argue, "[t]his is why achieving a blend at human scale will induce a feeling of global insight". No doubt, human scale and global insight are particularly relevant in any successful persuasion as they render it not only more intelligible, but also more appealing and useful to us as human beings. Referring once again to the excerpts in (5) and (6), we can conclude that this is why Barenboim has in all likelihood succeeded in persuasively conveying to the audience his idea of "inexpressible content of music".

Let us now consider an example of how, relying both on the verbal description and music, Barenboim translates to his audience his musicderived knowledge about the relation between an individual and a group.

(8) [T] he notes in music cannot be allowed to develop their natural egos, so that they hide the preceding one, but the expression in music comes from the linkage [...]. When we play five notes that are bound, each note fights against the power of silence that wants to make it die, and is therefore in relation to the preceding note and to the note that comes after that. So when you play five notes, [plays 5 notes] if each note

${ }^{8}$ See Footnote 6. 
had a big ego it would want to be louder than the note before. And therefore I learned from this very simple fact, that no matter how great an individual you are, music teaches you that the creativity only works in groups, and the expression of the group is very often larger than the sum of the parts. (L1)

The crux of this argument resides in elaborating the structure of the Musical Sound blend and portraying a musical sound as a person who, if not constrained, might develop his or her "natural ego" to a "big ego". In the context of the blend, the musical sound's ego corresponds to the sound's loudness in $\mathrm{I}_{1}$, and an increase in loudness corresponds to a "bigger ego" of a sound in the blend. This aspect of the blend is then back projected to $\mathrm{I}_{3}$ and $\mathrm{I}_{4}$ giving rise to a metaphorical correspondence which might be phrased as in (9):

(9) (GROWING OF) THE EGO IS (INCREASING) THE MUSICAL SOUND'S INHERENT LOUNDNESS.

It is the emergent logic of the blend that allows Barenboim to describe in a very simple and ingenious way the precondition for and the nature of creativity - the concept which, beyond doubt, is difficult to understand. In terms of this logic, to be creative even a "great individual" - be it a musician of $\mathrm{I}_{4}$ or any human being of $\mathrm{I}_{3}$ - cannot stay on his/her own. As in the case of a musical sound in the blend, creativity is only possible in a group which, moreover, comprises individuals who have managed to constrain the development of their "natural" egos into "big" egos. Clearly, the elaboration of the blend in (8) functions as the viewpoint from which one can characterize the nature of creativity and psychological development in music and in life, and, by the same token, it provides basis for further structuring of the Musician input $\left(\mathrm{I}_{4}\right)$ and of the Life of a Human Being input $\left(\mathrm{I}_{3}\right)$, which are in focus in (8).

It is evident also that the musical illustration of 5 notes referred to in the transcript in (8) makes sense only with reference to the emergent logic of the blend: the notes are played with equal degree of loudness, and thereby they exemplify "natural egos" of musical notes. Directly relevant to the present topic is the fact that this example is another instance of Barenboim's intermodal translation which relies on a verbo-musical metaphor. Specifically, the source and target of the metaphor (GROWING OF) is the EGO IS (INCREASING) THE MUSICAL SOUND'S INHERENT LOUDNESS are distributed across two modalities: the musical mode in conjunction with the verbal express its source, while the target is only expressed verbally. Note further that Barenboim presents this metaphor as his well-established pattern of thought. Undoubtedly, for members 
of the audience, this metaphor is completely novel, and they have to follow his guidance to establish the relevant correspondence on-line. And so, this might be a clear case of two alternative ways of activating the same metaphor - as a kind of "cognitive routine" and as a structure created on-line. ${ }^{9}$

The next example of Barenboim's intermodal translations and, presumably, of his routine way of thinking about life comes from his third lecture. In his argument, having recalled a question that he was confronted with as a small boy living in the Middle East - of why a single event in life may change our perception of whatever preceded it and whatever will follow - Barenboim goes on to explain that he got a clear understanding of this relationship between events from music. Referring to a musical example he later intends to play, he notes:

(10) [T] he moment where there comes a fantastic vertical pressure on the horizontal floor of the music, and that moment you know that the music cannot continue any more the way it was before, such as the world was not the same after the $9^{\text {th }}$ November of 1938 , or the $9^{\text {th }}$ November of 1989 , or the $11^{\text {th }}$ September of 2001 - events that have changed everything both towards the future and towards the past. [...] My point is that I learned the fact that there is a vertical pressure on the horizontal floor, that there is something that shows at a certain moment that we have to accept the inevitability of something that has changed our life. (L3)

The specific novel metaphor that he employs can be stated as in (11):

(11) A CRITICAL EVENT (IN THE COURSE OF LIFE) IS VERTICAL PRESSURE (ON THE HORIZONTAL FLOOR OF MUSIC).

The musical example played to support the argument consisted of a few bars from the last movement of the ninth symphony by Beethoven where the text of the Ode to Joy is: "und der Cherub steht vor Gott, vor Gott" ('and the cherub stands before God'). Observe that the up/down and the force image schemas (Johnson1987), which provide the structure and basic logic of the source domain of this metaphor, are evoked first through language (cf. vertical pressure, horizontal floor in (10)), and then by means of pitch and volume of the music played. Therefore, I will regard it as another instance of a verbo-musical metaphor in Barenboim's discourse. Undoubtedly, depending on their musical knowledge and experience, the members of the audience are bound to differ in their understanding of this metaphor. And in particular, for those of the members who are used to

${ }^{9}$ For a study of creative metaphors in argumentative texts which allow for differences in meaning construction between writers and readers and between different groups of readers, see Semino (2012). 
attentive listening, the musical mode would provide far more specific and rich understanding of the metaphorical source than for those members who take music as a mere pastime or background noise.

The example in (10) raises two further questions to which we may now turn: why the FORCE and the UP/DOWN (or, the VERTICALITY) image schemas are employed and why music is described as horizontal. The use of the VERTICALITY schema in the characterization of musical pitch is, on Zbikowski's account, quite straightforward:

(12) when we make low sounds, our chest resonates; when we make high sounds, our chest no longer resonates in the same way, and the source of sound seems located nearer our head. The 'up' and 'down' of musical pitch thus correlate with the spatial 'up' and 'down' - the vertical orientation - of our bodies. (Zbikowski 2000: 6)

Moreover, the bodily sensations associated with the production of high and low pitches are, as Zbikowski claims, just one aspect of our embodied experience of musical pitch. Crucially, embodied imageschematic structure of spatial concepts can be metaphorically projected onto the acoustic domain. Specifically,

(13) [B]oth space and the frequency spectrum are continua that can be divided into discontinuous elements. In the spatial domain, division of the continuum results in points; in the acoustic domain it results in pitches. Mapping of [the spatial] UP/ DOWN onto pitch allows us to import the concrete relationships through which we understand physical space into the domain of music, and thereby provide a coherent account of relationships between musical pitches. (Zbikowski 2000: 7)

In brief, for Zbikowski, there is a direct bodily motivation for the conceptual metaphor given in (14):

(14) PITCH RELATIONSHIPS ARE RELATIONSHIPS IN VERTICAL SPACE.

Importantly, the musical passage played by Barenboim involved a very abrupt fall down the musical scale, and thereby it functioned as - to use Zbikowski's term (2009: 363) - a sonic analog of Barenboim's verbal characterization of critical events in life in terms of vertical (pressure). ${ }^{10}$

Note that the use of the expression pressure itself indicates that the FORCE schema has also been activated. The application of the force schema to the music domain might be said to reflect our embodied experience of a higher volume sound whose production requires more force as compared to a sound having a lower volume; in the case in point, the force schema is also motivated by our understanding of the sudden change in pitch and volume in terms of (caused) motion (cf. the metaphors

${ }^{10}$ For more on the up/down orientation in music, see Górska 2014c. 
CHANGES ARE MOVEMENTS and COUSES ARE FORCES, Lakoff and Johnson 1999: 179-188).

And why is (the floor of) music horizontal? This might be motivated by the idea of pitch and volume as having one particular level during the relevant musical "chunk" (with respect to our common experience of force, we could say that here a particular force vector follows a single path of motion); when affected by abrupt pressure, such a musical "chunk" can no longer continue in the same way (since the original force-vector has been diverted to a different path of motion).

Beyond doubt, the shifts between language and music in constructing one argument contribute to Barenboim's rhetorical originality. Crucially, the fact that two modalities are involved in activating the notions of VERTICALITY and FORCE increases the degree of contextual activation of the motivating image schemas and of the metaphorical correspondence itself, and in effect renders Barenboim's insight into critical events in life more memorable.

My final example of Barenboim's intermodal translations illustrates his views on why a resolution of long-term peace process fails. Arguing that "we have to teach our children [...] about the connection between music and real life", Barenboim shifts the topic again to things he has himself learnt from music. And to "demonstrate", as he put it, one such thing, he reconstructed the way he managed to find a resolution in his debate with his friend Edward Said (a Palestinian intellectual), over the Oslo Process. ${ }^{11}$ For a long time they kept having very lively arguments until one day Barenboim said to his friend:

(15) It doesn't really matter if Oslo is right or wrong, it will never work because the relation between content and time is erroneous [...]. This I have learned from music [...]. The preparation for the beginning of the Oslo discussions was practically non-existent, much too quick. And the process itself, once the discussion started, was very slow, and then it was interrupted, and then they said they would meet next Tuesday, and then it was cancelled on Monday, and then they met again a month later, and everything. It had no chance. And I sat down at the piano and I showed to him what I meant. (LD1)

At this point, Barenboim played a few bars of a very majestic, slow introduction of the Pathetique Sonata of Beethoven, and then moved on to play a few bars of the main movement - Allegro, and recalled that he had told his friend that "Oslo, the equivalent of Oslo would be if

11 The term "Oslo Process" refers to the Palestinian-Israeli political process that started in 1993 with the aim to end the Palestinian-Israeli conflict. The process was supposed to have been completed by May 1999, yet due to many delays and periodic outbursts of violence it failed to produce a permanent agreement. 
I would play the introduction very fast and without any preparation of anything - in other words: [he played a few bars of the introduction at an extremely fast tempo], and commented: "You would not understand anything what I am doing. And then I would get to the main allegro and I will play": [he played only one note from the allegro], which made his audience respond with laughter; then he continued to play the allegro at an extremely slow tempo-a few more notes at a time with long pauses, to which his audience reacted with applause. Finally, he closed up his argument by saying that his discussion with his friend Said "stopped from that moment on about Oslo because we both agreed it wouldn't work, for different reasons" (LD1).

In this case, the specific verbo-musical metaphor can be stated as in (16):

(16) A SUCCESSFUL EVENT SCHEDULE IS AN APPROPRIATE RELATION BETWEEN CONTENT AND TIME IN MUSIC.

At the verbal level, this metaphor extends over the paragraph in (15), providing understanding of why the timing of the events as Barenboim has described it could not lead to a successful outcome of the Oslo process. And, here again, Barenboim's musical prompts work jointly with his verbal message (cf. the "content" is a particular fragment of the musical piece and "time" refers to the tempo at which this fragment is played). There seems to be hardly any doubt that Barenboim's communication via the verbo-musical mode was crystal clear to his audience - they reacted with laughter and applause. This reaction strongly indicates that the presently considered verbo-musical metaphor functioned as a successful means of communication which provided a clear understanding of the situation at hand. It needs to be emphasized, however, that when Barenboim used the same verbo-musical metaphor in his debate with Edward Said, it provided not only an understanding of the situation to which they both could agree (although "for different reasons"), but - more importantly - it brought about a change in their actions and behaviour - they stopped arguing.

\section{Conclusion}

In earlier studies of intermodal shifts between music and language the focus was on what musicians call "text painting", in which music accompanying a particular text of a vocal work is meant to suggest or 
"paint" an image that is referred to in the text itself (see Zbikowski 2006; 2008; 2009). Seen in this light, Barenboim's intermodal shifts are a unique case for a number of reasons. First, taking his lifelong experience of music as a metaphorical source domain via which he has learnt a lot about the domain of life, Barenboim uses the verbal mode either alone or in combination with the musical modality aiming to convey his main objective of convincing the BBC Reith lectures' audience that they can get a deeper insight into life through music - provided they do not treat music as something merely "ornamental", "enjoyable" and "exciting", but as something "essential" (L3). Crucially, through their multimodal construction and Barenboim's explicit characterizations, the verbo-musical metaphors are in focal attention of the audience. The creative character of the metaphors may be considered yet another "metaphoricity indicator" contributing to their foregrounding. ${ }^{12}$ In effect, having achieved a very high degree of contextual activation, they function as a valuable rhetorical means of obtaining the persuasive goal and building an intersubjective relation with the audience.

Und oubtedly, depending on their musical knowledge and experience, the members of the audience are bound to differ in their understanding of the verbo-musical metaphors. And in particular, for those of the members who are used to attentive listening, the musical mode would provide a far more specific and rich understanding of the metaphorical source than for those members who take music as a mere pastime or background noise.

Note, finally, that Barenboim presents the verbo-musical metaphors as his well-established patterns of thought. For members of the audience, however, the various metaphorical mappings to the domain of LIFE are completely novel, and they have to follow his guidance to establish the relevant correspondences on-line. And so, this might be a case of two alternative ways of activating the same metaphors - as a kind of cognitive routine and as a structures created on-line.

\section{References}

Cienki, Alan, Cornelia Müller (2008). "Metaphor, Gesture, and Thought". In: The Cambridge Handbook of Metaphor and Thought. Ed. Raymond W. Gibbs. (483-501). Cambridge: Cambridge University Press.

${ }^{12}$ Górska (2017a) argues that, aside the observable metaphoricity indicators discussed by Müller (2008: 198; see also Footnote 6), the novelty of the mapping should also be included among the factors that may increase the metaphor's activation level. 
Dancygier, Barbara, Eve Sweetser (2014). Figurative Language. Cambridge: Cambridge University Press.

Fauconnier, Gilles (1997). Mappings in Thought and Language. Cambridge: Cambridge University Press.

Fauconnier, Gilles, Mark Turner (1998). "Conceptual Integration Networks". Cognitive Science 22: 133-187.

Fauconnier, Gilles, Mark Turner (2002). The Way we Think. Conceptual Blending and the Mind's Hidden Complexities. New York: Basic Books.

Feyaerts, Kurt, Geert Brône, Bert Oben (2017). "Multimodality in Interaction". In: The Cambridge Handbook of Cognitive Linguistics. Ed. Barbara Dancygier. (135-156). Cambridge: Cambridge University Press.

Forceville, Charles (2013). "Metaphor and Symbol. Searching for One's Identity is Looking for a Home in Animation Film". Review of Cognitive Linguistics 11 (2): 250-268.

Forceville, Charles, Eduardo Urios-Aparisi (2009). "Introduction". In: Multimodal Metaphor. Eds. Charles Forceville, Eduardo Urios-Aparisi. (3-17). BerlinNew York: Mouton de Gruyter.

Górska, Elżbieta (2012/2010). "Life Is Music: A Case Study of a Novel Metaphor and Its Use in Discourse". In: Textual Choices and Discourse. A View from Cognitive Linguistics. Eds. Barbara Dancygier, José Sanders, Lieven Vandelanotte. (137-155). Amsterdam: Benjamins. / English Text Construction 3 (2): 275-293.

Górska, Elżbieta (2014a). “Why Are Multimodal Metaphors Interesting? The Perspective of Verbo-Visual and Verbo-Musical Modalities. In: From Conceptual Metaphor Theory to Cognitive Ethnolinguistics. Patterns of Imagery in Language. Eds. Marek Kuźniak, Agnieszka Libura, Michał Szawerna. (17-36). Frankfurt am Main: Peter Lang.

Górska, Elżbieta (2014b). „Dynamiczne podejście do metafory” [Dynamic Approach to Metaphor]. Prace Filologiczne 64 (2): 109-122.

Górska, Elżbieta (2014c). "The Up/Down Orientation in Language and Music". In: The Body in Language. Comparative Studies of Linguistic Embodiment. Eds. Matthias Brenzinger, Iwona Kraska-Szlenk. (177-195). Leiden: Brill.

Górska, Elżbieta (2017a). "The Path Schema in Verbo-Pictorial Aphorisms on Life". In: The Route Sixty-Six: From Deep Structures to Surface Meanings. A Festschrift for Henryk Kardela on His $66^{\text {th }}$ Birthday. Eds. Przemysław Łozowski and Adam Głaz. (219-235). Lublin: Wydawnictwa UMCS.

Górska, Elżbieta (2017b). “Text-image Relations in Cartoons. A Case Study of Image Schematic Metaphors". Studia Linguistica Universitatis Iagellonicae Cracoviensis [Special issue: Cognitive Linguistics] 134 (3): 219-228.

Hampe, Beate (2017). "Embodiment and Discourse: Dimensions and Dynamics of Contemporary Metaphor Theory". In: Metaphor, Embodied Cognition, and Discourse. Ed. Beate Hampe. (3-23). Cambridge: Cambridge University Press.

Johnson, Mark (1987). The Body in the Mind: The Bodily Basis of Imagination, Reason, and Meaning. Chicago: University of Chicago.

Kolter, Astrid, Silva H. Ladewig, Michela Summa, Cornelia Müller, Sabine C. Koch, Thomas Fuchs (2012). “Body Memory and The Emergence 
of Metaphor in Movement and Speech. An Interdisciplinary Case Study". In: Body Memory, Metaphor and Movement. Eds. Sabine C. Koch, Thomas Fuchs, Michela Summa, Cornelia Müller. (201-226). Amsterdam: Benjamins. Lakoff, George, Mark Johnson (1999). Philosophy in The Flesh: The Embodied Mind and its Challenge to Western Thought. New York: Basic Books.

Langacker, Ronald W. (1987). Foundations of Cognitive Grammar. Vol. 1: Theoretical Prerequisites. Stanford: Stanford University.

Libura, Agnieszka (2007). „Amalgamaty kognitywne. Powstanie i rozwój koncepcji integracji pojęciowej" [Conceptual Blends. The Development of Conceptual Integration Theory]. In: Amalgamaty kognitywne w sztuce [Conceptual Blends in Art]. Ed. Agnieszka Libura. (11-66). Kraków: Universitas.

Müller, Cornelia (2008). Metaphors Dead and Alive, Sleeping and Waking. A Dynamic View. Chicago: University of Chicago.

Müller, Cornelia, Susanne Tag (2010). “The Dynamics of Metaphor: Foregrounding and Activating Metaphoricity in Conversational Interaction". Cognitive Semiotics 6: 85-120.

Oakley, Todd, Esther Pascual (2017). "Conceptual Blending". In: The Cambridge Handbook of Cognitive Linguistics. Ed. Barbara Dancygier. (423-448). Cambridge: Cambridge University Press.

Semino, Elena (2012). "Unrealistic Scenarios, Metaphorical Blends and Rhetorical Strategies across Genres". In: Textual Choices and Discourse. A View from Cognitive Linguistics. Eds. Barbara Dancygier, José Sanders, Lieven Vandelanotte. (111-135). Amsterdam: Benjamins.

Szawerna, Michał (2017). Metaphoricity of Conventionalized Diegetic Images in Comics. A Study in Multimodal Cognitive Linguistics. Frankfurt am Main: Peter Lang.

Vandelanotte, Lieven (2017). “Viewpoint". In: The Cambridge Handbook of Cognitive Linguistics. Ed. Barbara Dancygier. (157-171). Cambridge: Cambridge University Press.

Zbikowski, Lawrence M. (2000). “Des Herzraums Abschied: Mark Johnson's Theory of Embodied Knowledge and Music Theory". Theory and Practice 22/23: 1-16. URL: http://humanities.uchicago.edu/faculty/zbikowski/pdfs/Zbikowski_ Des_Herzraums_Abschied.pdf [ed. Mar. 1, 2009].

Zbikowski, Lawrence (2006). "The Cognitive Tango". In: The Artful Mind. Cognitive Science and the Riddle of Human Creativity. Ed. Mark Turner. (115-131). Oxford: Oxford University.

Zbikowski, Lawrence (2008). "Metaphor and Music". In: The Cambridge Handbook of Metaphor and Thought. Ed. Raymond W. Gibbs. (502-523). Cambridge: Cambridge University.

Zbikowski, Lawrence (2009). "Music, Language, and Multimodal Metaphor". In: Multimodal Metaphor. Eds. Charles Forceville, Eduardo Urios-Aparisi. (359-381). Berlin: Mouton de Gruyter. 


\section{Data Sources with Abbreviations Used}

L1/LD1 - Lecture 1 (\& discussion): In the Beginning Was Sound, Delivered by Daniel Barenboim at Cadogan Hall. London: BBC Radio. Reith Lectures 2006. URL: http://www.bbc.co.uk/radio4/reith2006/lecture1.shtml [ed. June 10, 2006].

L2/LD2 - Lecture 2 (\& discussion): The Neglected Sense, Delivered by Daniel Barenboim at Symphony Centre. Chicago: BBC Radio. Reith Lectures 2006. URL: http://www.bbc.co.uk/radio4/reith2006/lecture2.shtml [ed. June 10, 2006].

L3/LD3 - Lecture 3 (\& discussion): The Magic of Music, Delivered by Daniel Barenboim at the Berlin State Opera. BBC Radio. Reith Lectures 2006. URL: http://www.bbc.co.uk/radio4/reith2006/lecture3.shtml [ed. June 10, 2006].

L4/LD4 - Lecture 4 (\& discussion): Meeting in Music, Delivered by Daniel Barenboim in Jerusalem. BBC Radio. Reith Lectures 2006. URL: http://www. bbc.co.uk/radio4/reith2006/lecture4.shtml [ed. June 10, 2006].

L5/LD5 - Lecture 5 (\& discussion): The Power of Music, Delivered by Daniel Barenboim in Jerusalem. BBC Radio. Reith Lectures 2006. URL: http://www. bbc.co.uk/radio4/reith2006/lecture5.shtml [ed. June 10, 2006]. 